\title{
Clonal relationships, antimicrobial susceptibilities, and molecular characterization of extended-spectrum beta-lactamase-producing Escherichia coli isolates from urinary tract infections and fecal samples in Southeast Iran
}

\author{
Zahra Hashemizadeh ${ }^{[1]}$, Davood Kalantar-Neyestanaki ${ }^{[1],[2]}$ and Shahla Mansouri[ ${ }^{[1],[3]}$
}

[1]. Department of Microbiology and Virology, School of Medicine, Kerman University of Medical Sciences. Kerman, Iran.

[2]. Student Research Committee, School of Medicine, Kerman University of Medical Sciences, Kerman, Iran.

[3]. Research Center for Infectious Diseases and Tropical Medicine, Kerman, Iran.

\begin{abstract}
Introduction: Multidrug-resistant (MDR) Escherichia coli, a species that is a leading cause of urinary tract infections (UTIs) and is a major global public health concern. This study was designed to detect the differences in antibiotic resistance patterns, the production and type of extended spectrum $\beta$-lactamases (ESBLs), and the clonal relationships among $E$. coli isolates from UTIs and fecal samples. Methods: Antibacterial resistance was determined by the disk diffusion method. ESBL, carbapenemase, and AmpC-producing isolates were detected phenotypically. Then, the ESBL genes were sequenced to detect the type. Enterobacterial repetitive intergenic consensus-polymerase chain reaction (ERIC-PCR) was performed on the ESBL-positive isolates. Results: The most common effective antibacterial agents were colistin, imipenem, and amikacin. Among the isolates, $204(56.6 \%)$ were MDR. Of the 163 ESBL-positive isolates, 11 (6.7\%) produced AmpC, and the frequencies of beta-lactamase-positive genes were as follows: $b l a_{\text {CTX-Mgroup }}, 76 \%$; $b l a_{\text {TEM1 }}, 74.8 \% ; b l a_{\text {SHV12 }}, 1.2 \%$; and $b l a_{\text {OXA1 }}, 12.88 \%$. ERIC PCR showed a diverse pattern, suggesting that clonal spread of $E$. coli in this area is uncommon, and that most of the infecting strains are endogenous. Conclusions: The high rates of antibacterial-resistant and MDR isolates are quite important since these strains can act as source of resistant bacteria that can be spread in the community. Controlling antibiotic use, against inappropriate use and abuse, in the community and continuous surveillance of emerging resistance traits are critical to controlling the spread of resistance.
\end{abstract}

Keywords: Escherichia col. Antimicrobial resistance. ESBL. AmpC beta-lactamas.

\section{INTRODUCTION}

Escherichia coli is found in the normal microbiota of the human intestinal tract, and it has an important role in protecting against pathogenic bacteria ${ }^{1}$. An estimated $70-90 \%$ of community-acquired urinary tract infections (UTIs) and $50 \%$ of hospital-acquired UTIs are caused by E. coli ${ }^{2}$. Most nosocomial UTIs are caused by endogenous strains, although exogenous infections from other patients or other sources have also been documented ${ }^{3}$.

Many antibacterial agents, such as beta-lactams and fluoroquinolones, are recommended for the treatment of UTIs ${ }^{4}$. However, inappropriate use and overuse of antibacterial agents have resulted in the emergence of multidrug-resistant (MDR) isolates; therefore, the drugs previously used to treat patients, such as fluoroquinolones, trimethoprim/sulfamethoxazole,

Corresponding author: Dr. Shahla Mansouri.

e-mail: smansouri@kmu.ac.ir

Received 29 June 2017

Accepted 20 December 2017 and cephalosporin, have become ineffective ${ }^{4}$. Beta-lactams are the most commonly used antimicrobial agents for the treatment of UTIs ${ }^{5}$. The main mechanism of resistance to beta-lactams is the production of beta-lactamase enzymes ${ }^{5}$. Beta-lactamase enzymes, such as extended spectrum betalactamases (ESBLs), metallo-beta-lactamases (MBLs), and AmpC beta-lactamase, have been reported in gram-negative bacteria ${ }^{6}$. When these resistant bacterial isolates cause hospitaland community-acquired infections, treatment is difficult since the therapeutic options are limited ${ }^{5}$. Beta-lactamase genes are usually encoded on mobile genetic elements that can be easily transmitted between different bacterial species or strains ${ }^{7}$. Therefore, epidemiological studies are crucial for monitoring drug resistance among bacterial isolates and determining the distribution of drug resistance in the community. In this study, the antibacterial resistance profiles, frequency of ESBL genes, and clonal relationships among isolates from fecal samples and the urinary tracts of inpatients and outpatients with UTIs was determined to find better strategies for the control and management of UTIs caused by E. coli. 


\section{METHODS}

\section{Study population and bacterial isolates}

From October 2014 to June 2015, 351 E. coli strains (100 from inpatients with UTIs and 151 from outpatients with UTIs) were isolated in Kerman, Iran. The patients were considered inpatients when they stayed in a given hospital ward for treatment for $\geq 48 \mathrm{~h}$ and/or within 30 days of hospital discharge, otherwise they were considered outpatients. Outpatients were those who visited the emergency ward with acute symptoms or were referred to local private laboratories for urine culture. All outpatients were not previously hospitalized due to any disease ${ }^{8}$. Fecal samples $(\mathrm{n}=100)$ were collected by individual rectal swabs from volunteers without any digestive problems and were transported to the laboratory in Cary-Blair transport medium and then placed overnight in buffered peptone water at $37^{\circ} \mathrm{C}$. The samples were then cultivated on MacConkey agar (CONDA, Co., SPAIN). Lactose-positive isolates on MacConkey agar were selected for biochemical confirmatory tests for E. coli. The criteria for selection were no history of hospitalization and signs or symptoms of UTI or gastrointestinal symptoms, such as nausea, vomiting, abdominal cramps, diarrhea, fever, and headache. All isolates were confirmed to be $E$. coli by the results of standard biochemical tests, including gram-negative, oxidase negative, catalase positive, lactose positive, MR positive, VP negative, Indole positive, and acid/acid and gas positive on TSI medium? .

\section{Determination of antibacterial susceptibility and ESBL, AmpC, and carbapenemase production}

The standard disk diffusion method was used to determine the antibacterial susceptibility profiles of the isolates to 11 antibacterial agents ${ }^{10}$. The following disks (obtained from MAST Chemical Company, England) were used in this study: amoxicillin/clavulanic acid (AUG, 30/10 $\mu \mathrm{g}$ ), cefotaxime (CTX,

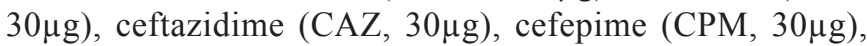
imipenem (IMP, $10 \mu \mathrm{g}$ ), ciprofloxacin (CIP, $10 \mu \mathrm{g})$, nalidixic acid (NA, $30 \mu \mathrm{g}$ ), trimethoprim (TM, $5 \mu \mathrm{g}$ ), piperacillin/tazobactam (PIP, $100 / 10 \mu \mathrm{g}$ ), amikacin (AK, 30 $\mathrm{g}$ ), and gentamicin $(\mathrm{GM}, 10 \mu \mathrm{g})$. MDR isolates were defined as described by Magiorakos et al. ${ }^{11}$. The European Committee on Antimicrobial Susceptibility Testing (EUCAST) guidelines were used to test for susceptibility to colistin $(\mathrm{CO}, 10 \mu \mathrm{g})^{12}$. However, the MIC by E-test (HiMedia, Co., India) was determined for isolates that were not susceptible to colistin in the disk diffusion for confirmation ${ }^{12,13}$. ESBL-producing isolates were identified by the combined disk method with clavulanic acid and extendedspectrum cephalosporins (CPD, CTX, and CAZ; $30 \mu \mathrm{g}$ alone and in combination with $10 \mu \mathrm{g}$ of clavulanic acid) ${ }^{14}$. The AmpC disk test was used to detect AmpC beta-lactamases as described by Black et al. ${ }^{15}$. The modified Hodge test (MHT) was used to detect carbapenemase-producing isolates ${ }^{10}$. E. coli ATCC 25922 and Pseudomonas aeruginosa ATCC 27853 were used as standard strains in the antibacterial susceptibility testing, and Klebsiella pneumoniae ATCC 700603 was used as the positive control for the ESBL test.

\section{Polymerase chain reaction to detect beta-lactamase genes}

The boiling method was used to prepare template DNA for PCR as described by Qi et al. ${ }^{16}$. The oligonucleotide primers used to detect $b l a_{\text {CTX-M group 1-4 }}, b l a_{\mathrm{TEM}}, b l a_{\mathrm{SHV}}, b l a_{\mathrm{OXA}}, b l a_{\mathrm{PER}}$, $b l a_{\mathrm{KPC}}$, and $b l a_{\mathrm{NDM}}$ are listed in Table $\mathbf{1}^{17-20}$. PCR amplification was performed in a total volume of $50 \mu \mathrm{L}$ containing $1 \mu \mathrm{L}$ of each primer $(10 \mathrm{pM}), 25 \mu \mathrm{L}$ of DNA Polymerase Master Mix RED (Ampliqon, Co., Denmark), $2 \mu \mathrm{L}$ of DNA, and $21 \mu \mathrm{L}$ of DNase and RNase free water in a FlexCycler PCR Thermal Cycler (Analytik Jena, Germany) under the following cycling conditions: an initial denaturation step at $95^{\circ} \mathrm{C}$ for $5 \mathrm{~min}$ followed by 30 cycles of denaturation at $95{ }^{\circ} \mathrm{C}$ for $1 \mathrm{~min}$, annealing at $55-61^{\circ} \mathrm{C}$ for $1 \mathrm{~min}$ (Table 1), extension at $72^{\circ} \mathrm{C}$ for $1 \mathrm{~min}$, and a final extension step at $72^{\circ} \mathrm{C}$ for $5 \mathrm{~min}$. The PCR products were separated by electrophoresis in a $1.5 \%$ agarose gel in 0.5 Tris, EDTA, Boric acid (TBE) buffer. For each ESBL group, amplicons from randomized selected strains were sequenced (Macrogen, South Korea). The obtained nucleotide sequences were compared with those in the GenBank database for homologous nucleotide sequences by BLAST (www.ncbi.nih.gov/BLAST program).

\section{Molecular typing of ESBL isolates by ERIC-PCR}

Enterobacterial repetitive intergenic consensus-polymerase chain reaction (ERIC-PCR) was used to determine the clonal relationships among the isolates using the ERIC2 primer (5'-AAGTAAGTGACTGGGGTGAGC-3' $)^{21}$. The ERIC-PCR amplifications were carried out in a total volume of $25 \mu \mathrm{L}$ containing $1 \mu \mathrm{L}$ of ERIC2 primer $(10 \mathrm{pM}), 12.5 \mu \mathrm{L}$ of DNA Polymerase Master Mix RED, $1 \mu \mathrm{L}$ of DNA template, and $10 \mu \mathrm{L}$ of DNase and RNase free water (SinaClon BioScience, Co., Iran) in a FlexCycler PCR Thermal Cycler under the following cycling conditions: an initial denaturation step at $95^{\circ} \mathrm{C}$ for $5 \mathrm{~min}$ followed by 30 cycles of denaturation at $95^{\circ} \mathrm{C}$ for $1 \mathrm{~min}$, annealing at $59^{\circ} \mathrm{C}$ for $1 \mathrm{~min}$, and extension at $72^{\circ} \mathrm{C}$ for $2 \mathrm{~min}$, and a final extension step at $72^{\circ} \mathrm{C}$ for $10 \mathrm{~min}$. The obtained PCR fragments were separated by electrophoresis in a $1.5 \%$ agarose gel, and the gel was analyzed by using Gel Compare software (BioMérieux, Applied Maths, Belgium) using a cut off of $70 \%$ to discriminate isolates ${ }^{22}$.

\section{Statistical analysis}

For data analysis, SPSS version 20.0 (IBM, Armonk, USA) was used. Fisher's exact test was used for data analysis and to evaluate the significance of differences. P value less than 0.05 was considered statistically significant.

\section{RESULTS}

\section{Antibacterial susceptibility}

All the tested isolates were susceptible to colistin. Although 10 isolates showed intermediate susceptibility to colistin by the disk diffusion method, the $\mathrm{E}$ test results showed that all isolates were sensitive, with an MIC $\leq 2 \mu \mathrm{g} / \mathrm{ml}$. The other most effective drugs were imipenem and amikacin (Table 2). There were significant differences in resistance to AUG, TM, NA, CTX, $\mathrm{CAZ}$, and PIT among the isolates from inpatient, outpatient, 
TABLE 1: PCR Primers used to amplify ESBL genes in Escherichia coli strains isolated from urinary tract infections and fecal samples.

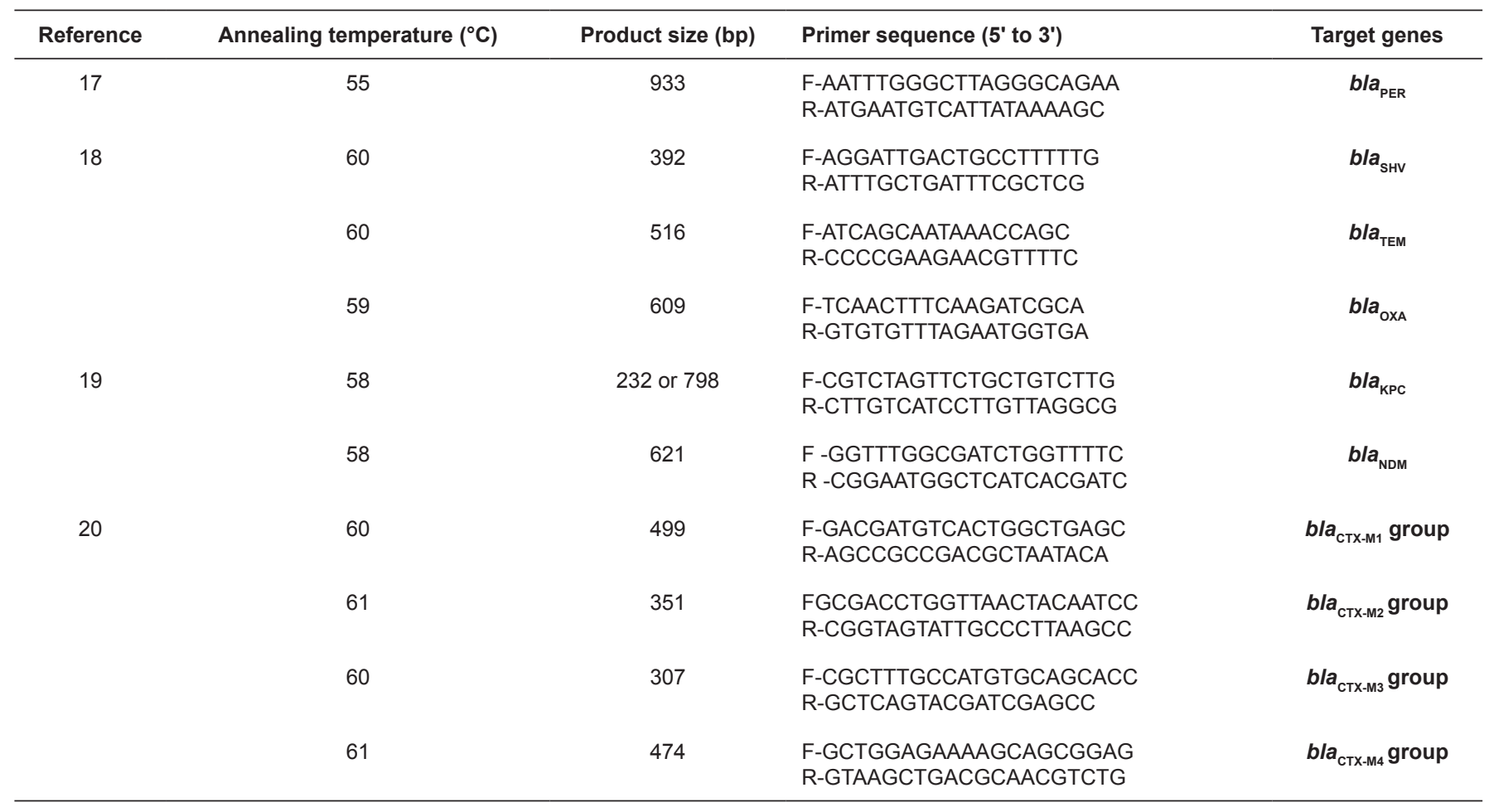

PCR: polymerase chain reaction; ESBL: extended spectrum $\beta$-lactamases.

TABLE 2: Antibacterial resistant patterns of 351 Escherichia coli isolates from in patients and outpatients with urinary tract infections and fecal samples.

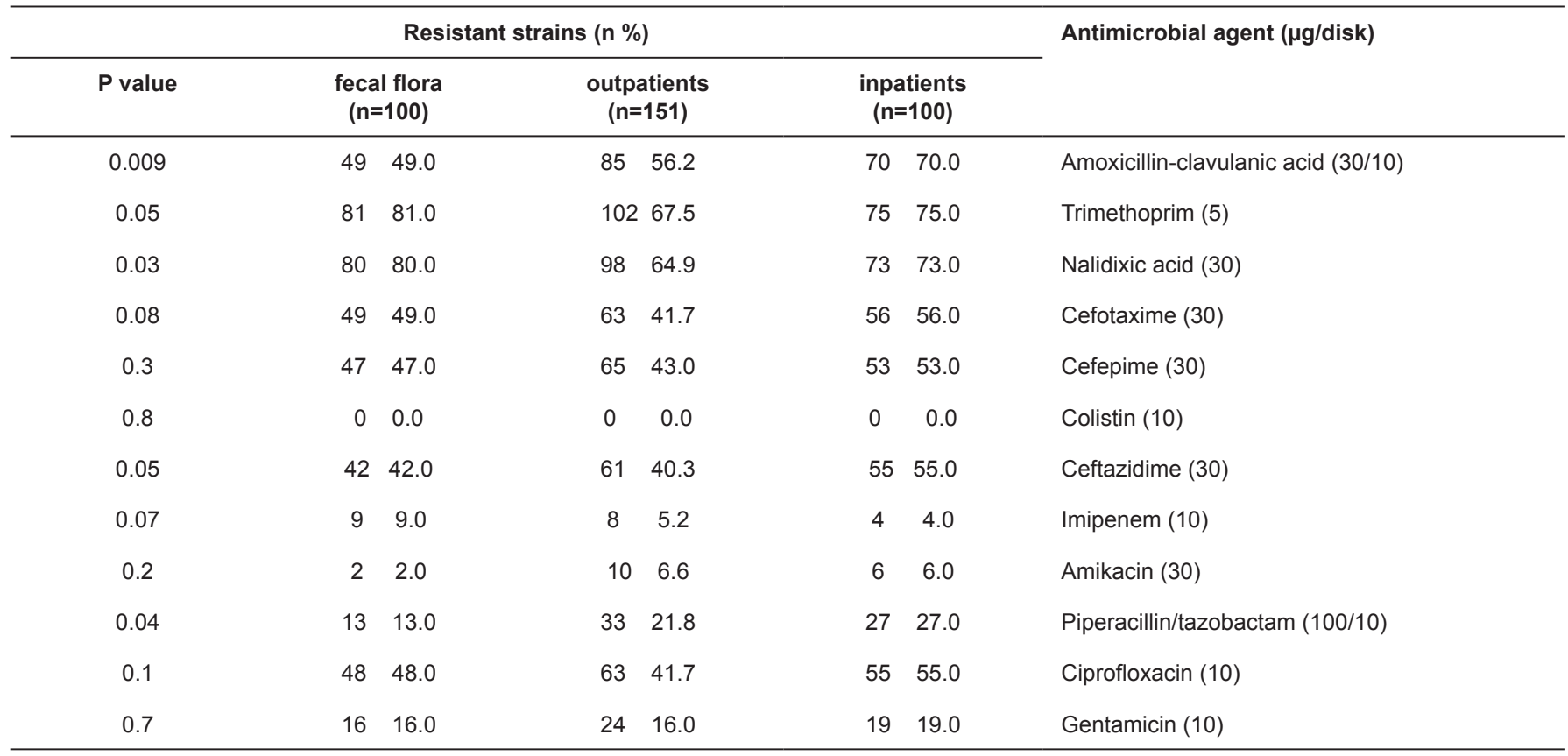

and fecal samples, and the resistance rates were significantly higher in inpatient samples than in outpatient and fecal samples ( $\mathrm{p} \leq 0.05)$. For TM and NA, a significantly higher rate of resistance was observed in fecal samples than in the inpatient and outpatient isolates $(\mathrm{p} \leq 0.05)$. There was no difference with respect to gender or age.
The rate of MDR, defined as resistance to at least three classes of antimicrobial agents, was high, and the MDR phenotype was detected in $61 \%, 55.6 \%$, and $57 \%$ of the inpatient, outpatient, and fecal isolates, respectively (Table 3). In the MDR isolates, the most frequent resistance pattern was to TM, NA, CPM, CAZ, CTX, and CIP (23 isolates, 11.3\%), 
TABLE 3: Antibiotic resistance patterns of 206 multidrug-resistant Escheriria coli isolates from UTIs and fecal samples.

\begin{tabular}{|c|c|c|c|c|}
\hline \multirow[t]{2}{*}{ Pattern of antibiotic resistance } & \multirow{2}{*}{$\begin{array}{l}\text { Total number of } \\
\text { isolates }\end{array}$} & \multicolumn{3}{|c|}{ Isolates according to sample source (n) } \\
\hline & & fecal flora & outpatient & inpatient \\
\hline AUG,TM,NA,CTX,CPM,CAZ,PIT,CIP,AK & 4 & - & 2 & 2 \\
\hline AUG,TM,NA,CTX,CPM,CAZ,PIT,CIP,GM & 10 & 2 & 3 & 5 \\
\hline AUG,TM,NA,CTX,CPM,CAZ,PIT,CIP & 16 & 4 & 6 & 6 \\
\hline AUG,TM,NA,CTX,CPM,CAZ,CIP,GM & 14 & 4 & 5 & 5 \\
\hline AUG,TM,NA,CTX,PIT,CIP,GM,AK & 11 & 1 & - & - \\
\hline AUG,TM,NA,CTX,CPM,CAZ,CIP,AK & 1 & 1 & - & - \\
\hline TM,NA,CTX,CPM,CAZ,PIT,CIP,GM & 1 & - & - & 1 \\
\hline AUG,NA,CTX,CAZ,PIT,CIP,GM,AK & 1 & - & - & 1 \\
\hline AUG,TM,NA,CTX,CPM,CAZ,CIP & 29 & 8 & 12 & 9 \\
\hline TM,NA,CTX,CPM,CAZ,PIT,CIP & 2 & - & 1 & 1 \\
\hline AUG,TM,NA,CTX,CPM,CAZ,PIT & 2 & - & 1 & 1 \\
\hline AUG,TM,NA,CTX,CPM,PIT,CIP & 1 & - & 1 & - \\
\hline AUG,TM,NA,CTX,PIT,CIP,GM & 1 & - & 1 & - \\
\hline AUG,TM,NA,PIT,CIP,GM,AK & 1 & 1 & - & - \\
\hline TM,NA,CTX,CPM,CAZ,CIP & 15 & 4 & 6 & 5 \\
\hline AUG,TM,NA,CTX,CPM,CAZ & 11 & 5 & 4 & 2 \\
\hline AUG,TM,NA,CTX,CIP,GM & 6 & 2 & 2 & 2 \\
\hline AUG,TM,CTX,CPM,CAZ,CIP & 4 & - & 2 & 2 \\
\hline AUG,TM,NA,CPM,PIT,CIP & 3 & - & 1 & 2 \\
\hline AUG,TM,NA,CTX,CAZ,CIP & 2 & - & - & 2 \\
\hline TM,NA,CTX,PIT,CIP,AK & 1 & - & - & 1 \\
\hline TM,CTX,CPM,CAZ,PIT,CIP & 1 & - & 1 & - \\
\hline TM,NA,CTX,CPM,CAZ & 10 & 3 & 4 & 3 \\
\hline TM,NA,CTX,CPM,CIP & 5 & 1 & 2 & 2 \\
\hline AUG,TM,NA,CPM,CIP & 4 & 1 & 2 & 1 \\
\hline AUG,TM,NA,PIT,CIP & 4 & 1 & 2 & 1 \\
\hline AUG,TM,NA,CIP,GM & 2 & - & 1 & 1 \\
\hline AUG,TM,NA,CTX,CAZ & 2 & 2 & - & - \\
\hline AUG,TM,NA,CPM,CAZ & 1 & - & 1 & - \\
\hline AUG,TM,NA,CTX,GM & 1 & 1 & - & - \\
\hline AUG,NA,CTX,CPM,CAZ & 1 & - & 1 & - \\
\hline TM,NA,CTX,CAZ,CIP & 1 & - & - & 1 \\
\hline AUG,TM,CAZ,PIT,CIP & 1 & - & 1 & - \\
\hline AUG,TM,NA,CIP & 10 & - & 5 & 5 \\
\hline TM,NA,CTX,CIP & 2 & - & 1 & 1 \\
\hline TM,NA,PIT,CIP & 2 & - & 1 & 1 \\
\hline AUG,NA,CIP,GM & 2 & - & 1 & 1 \\
\hline NA,PIT,CIP,AK & 1 & - & 1 & - \\
\hline TM,NA,CTX,GM & 1 & 1 & - & - \\
\hline TM,NA,CTX,CAZ & 1 & - & 1 & - \\
\hline NA,CTX,CPM,GM & 1 & - & 1 & - \\
\hline TM,NA,CIP,GM & 1 & - & 1 & - \\
\hline AUG,TM,NA & 6 & 2 & 4 & - \\
\hline TM,NA,GM & 3 & - & 2 & 1 \\
\hline AUG,TM,NA & 3 & - & 3 & - \\
\hline TM,PIT,AK & 1 & - & 1 & - \\
\hline AUG,TM,CIP & 3 & - & 1 & - \\
\hline
\end{tabular}

UTIs: urinary tract infections; AUG: amoxicillin-clavulanic acid; TM: trimethoprim; NA: nalidixic acid; CTX: cefotaxime; CPM: cefepime; CO: colistin; CAZ: ceftazidime; IMP: imipenem; AM: amikacin; PIT: piperacillin/tazobactam; CIP: ciprofloxacin; GM: gentamicin. 
followed by AUG, TM, NA, CTX, CPM, CAZ, and CIP (20 isolates, 9.8\%; Table 3). The antimicrobial resistance patterns of 24 isolates were unique.

\section{Detection of ESBLs, AmpC, carbapenemase, and blagenes}

The frequency of ESBL-positive isolates, as determined by the combined disk test, was $46.4 \%$ (163) for all isolates, and was 53\% (53), $41 \%$ (62), and $48 \%$ (48) for inpatient, outpatient, and fecal isolates, respectively. Isolates from inpatients had a significantly higher rate of ESBLs compared to outpatient and fecal samples $(\mathrm{P}=0.000)$. Among the 163 ESBL-positive isolates, 11 (6.74\%) isolates were AmpC producers. The MHT was negative for all imipenem-resistant isolates. The rates of detection for the following ESBL genes by PCR: $b l a_{\mathrm{TEM}}, b l a_{\mathrm{SHV}}, b l a_{\mathrm{OXA}}$, and $b l a_{\mathrm{CTX}}$ Mgroup1 were $74.8 \%$ (122), 1.2\% (2), 12.88\% (21), and 76\% (124), respectively (Figure 1). The other tested beta-lactamase genes, $b l a_{\mathrm{PER}}, b l a_{\mathrm{CTX}-\mathrm{Mgroup} 2,3,4}, b l a_{\mathrm{KPC}}$ and $b l a_{\mathrm{NDM}}$, were not detected in any of the tested isolates. The rates of AmpC and $b l a_{\mathrm{TEM}}$ were significantly higher in isolates from inpatients than in isolates from outpatients $\left(\mathrm{P}=0.003\right.$; Figure 1). Sequencing of the bla $_{\text {СтХ- }}$ ${ }_{\text {Mgroup }}, b l a_{\mathrm{TEM}}, b l a_{\mathrm{OXA}}$, and $b l a_{\mathrm{SHV}}$ ESBL genes confirmed that they were $b l a_{\mathrm{CTX} \text {-Mgroupl }}, b l a_{\mathrm{TEM} 1}, b l a_{\mathrm{OXA1}}$, and $b l a_{\mathrm{SHV} 12}$, respectively.

\section{Genetic comparison of the}

\section{ESBL-producing Escherichia coli isolates by ERIC-PCR}

The ERIC-PCR amplified sequences produced a wellseparated, sharp band in agarose electrophoresis in the range of 100-3000bp as estimated with the Gene Ruler 100bp Plus DNA Ladder (Thermo Scientific, Co. Canada). The amplified sequences were analyzed by the UPGMA program (UPGMA clustering UN weighted pair-group method with arithmetic averages) using Gel Compare software (version 4.0). In the data analysis, a cutoff of $70 \%$ was used due to the high diversity of the isolates. With this cutoff, 31 clusters and 17 singletons were detected. The dendrogram showed one major cluster comprising 19 isolates, with 14 from inpatients and 5 from outpatients. The second major cluster included 8 UTI isolates, which were mostly from inpatients. The other clusters contained a combination of isolates from inpatient and outpatient UTIs and fecal samples (Figure 2).

\section{DISCUSSION}

UTIs are a major public health problem, both in hospitals and in the community. Drug resistance in E. coli, due to horizontal gene transfer, has resulted in the emergence of MDR isolates, which are difficult to treat. The bacteria that cause most UTIs are of an endogenous origin; therefore, the fecal flora is important, and is likely a source of resistance genes. In this study, the antimicrobial resistance of fecal and UTI isolates were compared. E. coli is an important cause of uncomplicated UTIs in women, and it is also one of the most common causes of septicemia and meningitis in newborn infants, diarrhea in children less than five years of age, pneumonia and other nosocomial infections, especially ESBL-producing isolates,

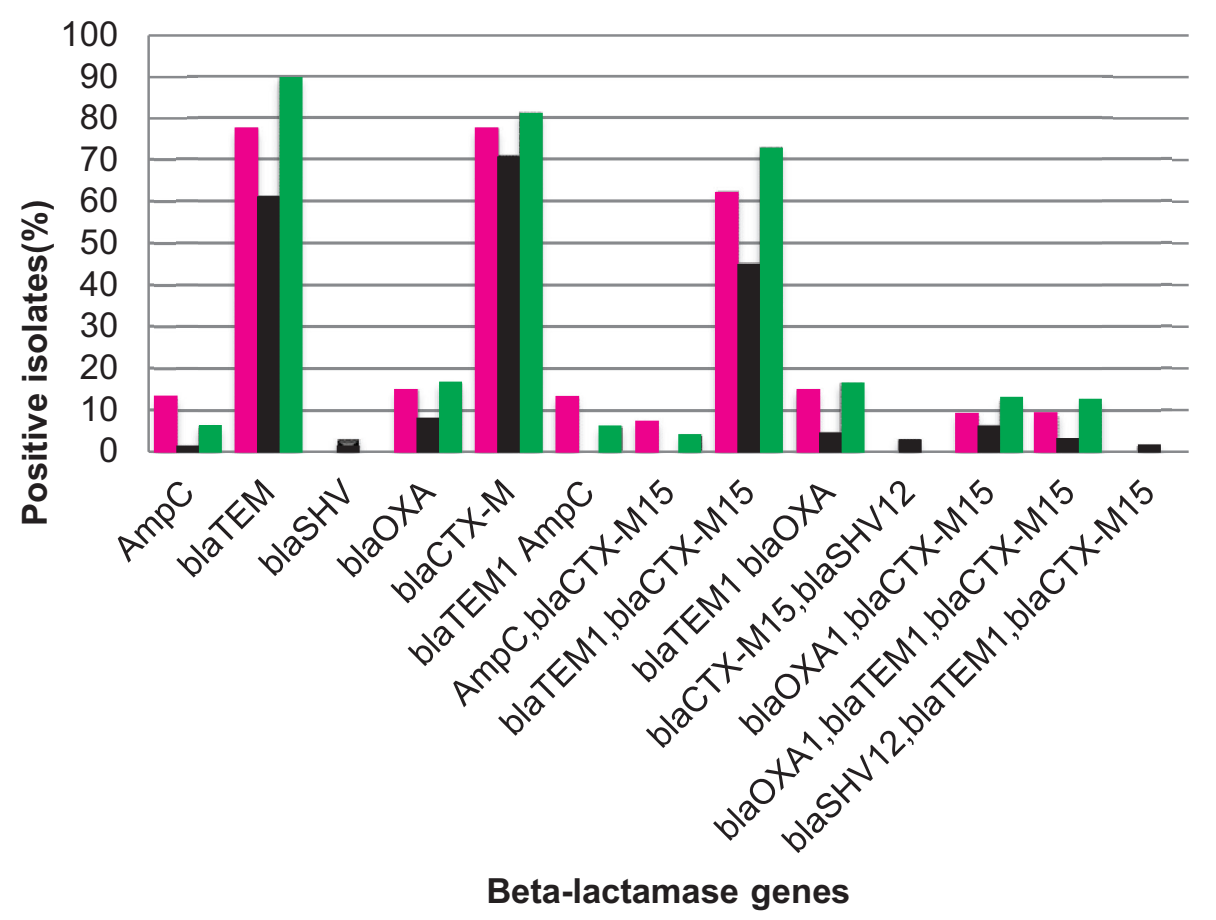

Inpatients $(n=53)$

Outpatients $(n=62)$

Fecal flora $(n=48)$

FIGURE 1: Distribution of ESBL genes and AmpC beta-lactamases among $163 \mathrm{ESBL}$-producing Escherichia coli isolates from urinary tract infections and fecal flora. ESBL: extended spectrum $\beta$-lactamases. 


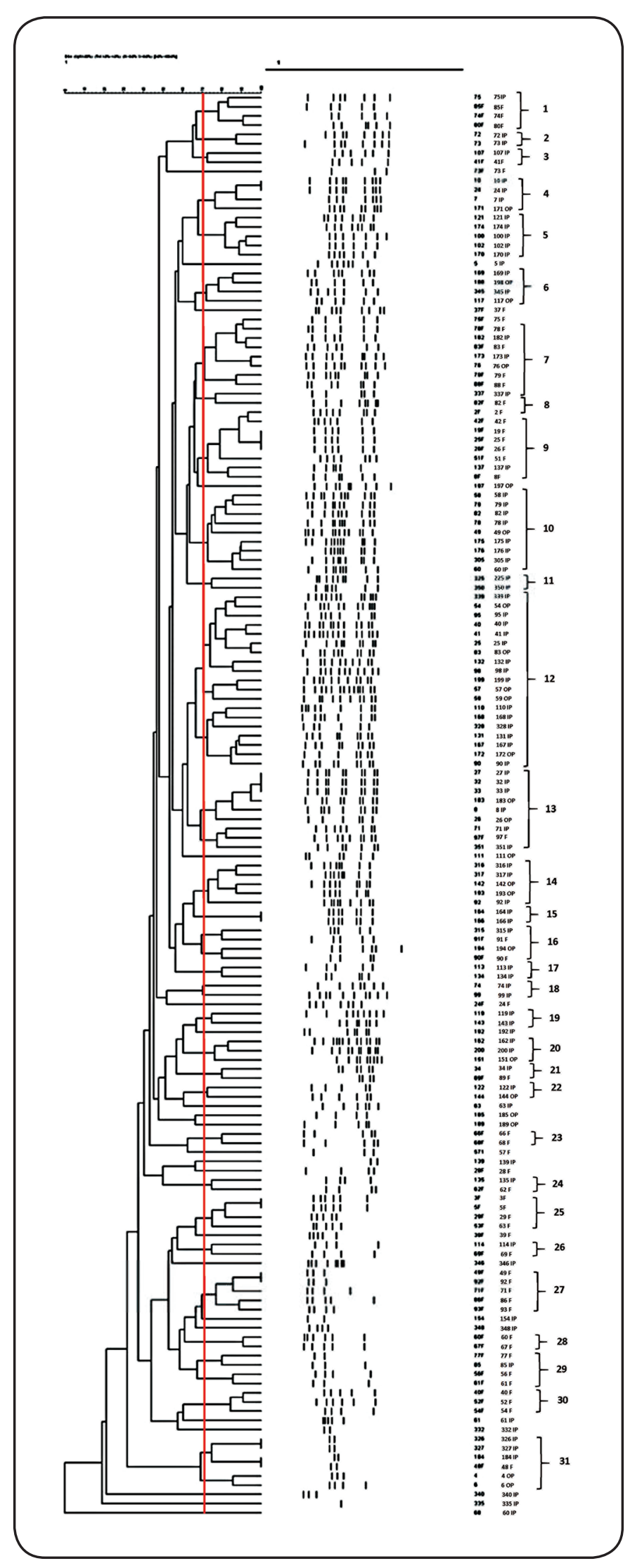

FIGURE 2: Dendrogram generated with ERIC-PCR data for ESBL-positive Escherichia coli isolates from UTIs and fecal flora. ERIC-PCR: enterobacterial repetitive intergenic consensus-polymerase chain reaction; ESBL: extended spectrum $\beta$-lactamases; UTIs: urinary tract infections; IP: inpatient; OP: outpatient; F: fecal sample. in immunocompromised and debilitated patients ${ }^{8}$. In recent years, the emergence of antimicrobial resistance has become an increasingly common factor in the management of patients with UTIs. Antibiotic resistance in $E$. coli isolates from women with uncomplicated UTIs has been reported in Germany, Spain, Sweden, and the $\mathrm{UK}^{23}$, and higher rates of resistance have been reported from non-European countries, such as India, China, and South Korea ${ }^{24-26}$. Our results also showed a high rate of resistance to various antimicrobial agents.

In a study performed in this area in 2002, the rates of resistance to various antimicrobial agents was much lower than those observed in the present study, and the sensitivity rates to GM, CTX, ZOX (ceftizoxime), and FM (nitrofurantoin) for fecal and UTI isolates were greater than $90 \%{ }^{27}$. This marked increase in resistance rates in a short time should be taken very seriously, and steps should be taken to reduce the rate of this increase. According to Walker et al. ${ }^{28}$ and based on other available literature, the rate of trimethoprim sensitivity remains high for most MDR E. coli isolates from UTIs. Commensal E. coli in the gastrointestinal tract are regarded as an important source of antibiotic-resistance genes, and these organisms can transfer resistance genes to other bacteria when exposed to antimicrobial agents ${ }^{29}$. In this study, the rates of resistance to amoxicillin-clavulanic acid and piperacillin/tazobactam were significantly higher in UTI isolates than in fecal isolates $(\mathrm{P} \geq 0.05)$. This demonstrates the important role of the fecal flora as a source of drug resistance in the community. The presence of antimicrobials in animal food for growth promotion and prophylaxis may be responsible for the emergence of antibacterial resistance strains in humans ${ }^{30,31}$. Simultaneous resistance to 5-9 antimicrobial agents was detected in 79.4\% of the isolates, while resistance to 3-4 antimicrobial agents was detected in $17.1 \%$ of the isolates. These results indicate that there is a shortage of available drugs for the treatment of UTIs.

ESBL-producing bacterial strains have spread worldwide, and nosocomial infections with ESBL-producing E. coli isolates are responsible for high rates of morbidity and mortality in infected patients ${ }^{32}$. Therefore, early detection and identification of ESBL-producing isolates are necessary to control the infection and prevent the spread of these organisms in hospitals and in the community. Significant associations have been reported for UTIs caused by ESBL-producing E. coli and male sex, residence in a nursing home, diabetes mellitus, and recurrent $\mathrm{UTIs}^{33}$. Other risk factors have also been reported, such as indwelling urinary catheters, old age, ventilation, and organ transplants or other surgery, as well as high-dose or longtime treatment with antimicrobials, especially beta-lactams and fluoroquinolones ${ }^{33}$. In the present study, $46.4 \%$ of the isolates were ESBL producers. However, isolates from outpatients had a significantly lower rate of ESBL production compared to isolates from inpatients and fecal samples. We did not find any difference in ESBL production according to age or gender. A high rate of ESBL-producing E. coli isolates from fecal samples has been reported by other researchers, and Leflon et al. ${ }^{30}$ reported an increase in the rate, from $0.6 \%$ to $6 \%$, over a five-year period in Paris, France. In the present study, we observed relatively 
high numbers of isolates producing bla $a_{\text {CTX-Mgroup } 1}(76 \%)$ and $b l a_{\mathrm{TEM}}(74.8 \%)$. The presence of $b l a_{\mathrm{CTX} \text {-Mgroup } 1}$ and $b l a_{\mathrm{TEM}}$ were significantly higher in isolates from fecal samples and UTIs of inpatients $(\mathrm{P}=0.0004)$. Recently, a higher rate of bla been reported in enteric bacteria, especially E. coli and Klebsiella pneumoniae, likely since the genes encoding these enzymes are located on plasmids or other mobile genetic elements. Because CTX-M family genes are present on plasmids or other mobile genetic elements, these enzymes have become predominant worldwide and are substituting for the more common SHV and $\mathrm{TEM}^{7,32}$. The most common type of CTX-M reported in various geographic regions is CTX-M15; these strains are usually MDR and are detected not only in nosocomial infections but also in the community $4,24,32$, and this result is in accordance with our finding of a high frequency of CTX-M15-producing E. coli isolates. The $b l a_{C T X-M}$-positive isolates in this study were MDR, showing resistance to fluoroquinolones, trimethoprim, tetracycline, and aminoglycosides, as well as non-carbapenem beta-lactamases, as was reported by Woodford \& Ward in $2004^{34}$. It has been suggested that CTX-M15 was disseminated by clonal expansion of the pandemic E. coli clone ST13124, which could also be the source of the genes observed in this study.

The genetic diversity of ESBL-producing E. coli isolates, as determined by ERIC-PCR, revealed the presence of diverse clonal groups (Figure 2). Similar results were observed according to the antimicrobial resistance patterns, with 42 different combinations of antimicrobial resistance. These results suggested that different strains of E. coli are widely distributed in this area, and empiric therapy is not recommended for the treatment of UTIs in this region.

Finally, we suggest that antimicrobial susceptibility testing should be performed to select the best available drug for the treatment of patients with UTIs. Due to high impact of CTX-M on public health, such as the difficultly in treating communityacquired UTIs, the spread of isolates producing ESBLs, especially CTX-M15 beta-lactamase, needs to be closely monitored. It could be concluded that in this area, inappropriate use or misuse of antimicrobial agents may be a cause of the high resistance rates instead of clonal spread of resistant strains.

\section{Financial support}

This research was supported by Kerman University of Medical Sciences \& Health Services grant no 94/497.

\section{Conflict of interest}

The authors declare that there is no conflict of interest.

\section{REFERENCES}

1. Riley L. Pandemic lineages of extraintestinal pathogenic Escherichia coli. Clin Microbiol Infect. 2014;20(5):380-90.

2. Pitout J. Extraintestinal pathogenic Escherichia coli: a combination of virulence with antibiotic resistance. Front Microbiol. 2012;3:(9):17.
3. Ezejiofor T. Environmental factors in renal disease: the contribution of urinary tract infections in Nigerian renal disease burden-research and minireview. Clin Microbiol. 2016;5(2):1-15.

4. Van der Bij AK, Peirano G, Pitondo-Silva A, Pitout JD. The presence of genes encoding for different virulence factors in clonally related Escherichia coli that produce CTX-Ms. Diagn Microbiol Infect Dis. 2012;72(4):297-302.

5. Paterson DL, Bonomo RA. Extended-spectrum $\beta$-lactamases: a clinical update. Clin Microbiol Rev. 2005;18(4):657-86.

6. Bush K. Overcoming $\beta$-lactam resistance in Gram-negative pathogens. Future Med Chem. 2016; 8(9):921-4.

7. Chong Y, Ito Y, Kamimura T. Genetic evolution and clinical impact in extended-spectrum $\beta$-lactamase-producing Escherichia coli and Klebsiella pneumoniae. Infect Genet Evol. 2011;11(7):1499-504.

8. Toval F, Köhler C-D, Vogel U, Wagenlehner F, Mellmann A, Fruth A, et al. Characterization of Escherichia coli isolates from hospital inpatients or outpatients with urinary tract infection. J Clin Microbiol. 2014;52(2):407-18.

9. Mahon CR, Lehman DC, Manuselis G.Textbook of diagnostic microbiology. $3^{\text {rd }}$ edition. Saint Louis, MO: Saunders Elsevier; 2007.

10. Clinical and Laboratory Standards Institute (CLSI). Performance Standards for Antimicrobial Susceptibility Testing; Twenty-Fourth Informational Supplement. CLSI M100-S24. 2014;34(1):50-57.

11. Magiorakos AP, Srinivasan A, Carey RB, Carmeli Y, Falagas ME, Giske CG, et al. Multidrug-resistant, extensively drug-resistant and pandrug-resistant bacteria: an international expert proposal for interim standard definitions for acquired resistance. Clin Microbiol Infect. 2012;18(3):268-81.

12. The European Committee on Antimicrobial Susceptibility Testing (EUCAST). Clinical breakpoints. Breakpoint tables for bacteria. Breakpoint tables for interpretation of MICs and zone diameters. Version 7.1, 2017. Available from: http://www.eucast.org/clinical_ breakpoints/

13. Galani I, Kontopidou F, Souli M, Rrkatsina PD, Koratzanis E, Deliolanis J, et al. Colistin susceptibility testing by E-test and disk diffusion methods. Int J Antimicrob Agents. 2008;31(5):434-9.

14. Weldhagen GF, Poirel L, Nordmann P. Amber class A extendedspectrum $\beta$-lactamases in Pseudomonas aeruginosa: novel developments and clinical impact. Antimicrob Agents Chemother. 2003;47(8):2385-92.

15. Black JA, Moland ES, Thomson KS. AmpC disk test for detection of plasmid-mediated ampc-lactamases in enterobacteriaceae lacking chromosomal AmpC- $\beta$-lactamase. J Clin Microbiol. 2005;43(7):3110-13.

16. Qi C, Pilla V, Jessica HY, Reed K. Changing prevalence of Escherichia coli with CTX-M-type extended-spectrum $\beta$-lactamases in outpatient urinary E. coli between 2003 and 2008. Diagn Microbiol Infect Dis. 2010;67(1):87-91.

17. Jiang J, Zhang Z, Li M, Zhou D, Ruan F, Lu Y. Detection of extendedspectrum $\beta$-lactamases in clinical isolates of Pseudomonas aeruginosa. Antimicrob Agents Chemother. 2006;50(9):2990-5.

18. Colom K, Pérez J, Alonso R, Fernández-Aranguiz A, Lariño E, Cisterna R. Simple and reliable multiplex PCR assay for detection of $b l a_{\mathrm{TEM}}, b l a_{\mathrm{SHV}}$ and $b l a_{\mathrm{OXA}-1}$ genes in Enterobacteriaceae. FEMS Microbiol Lett. 2003;223(2):147-51.

19. Poirel L, Walsh TR, Cuvillier V, Nordmann P. Multiplex PCR for detection of acquired carbapenemase genes. Diagn Microbiol Infect Dis. 2011;70:119-23.

20. Feizabadi MM, Delfani S, Raji N, Majnooni A, Aligholi M, Shahcheraghi F, et al. Distribution of bla ${ }_{\mathrm{TEM}}, b l a_{\mathrm{SHV}}, b l a_{\mathrm{CTX}-\mathrm{M}}$ genes 
among clinical isolates of Klebsiella pneumoniae at Labbafinejad Hospital, Tehran, Iran. Microb Drug Resist. 2010;16(1):49-53.

21. Meacham KJ, Zhang L, Foxman B, Bauer RJ, Marrs CF. Evaluation of genotyping large numbers of Escherichia coli isolates by enterobacterial repetitive intergenic consensus-PCR. J Clin Microbiol. 2003;41(11):5224-6.

22. Ardakani MA, Ranjbar R. Molecular typing of uropathogenic E. coli strains by the ERIC-PCR method. Electron Physician. 2016:8(4):22916.

23. Kahlmeter G, Ahman J, Matuschek E. Antimicrobial resistance of Escherichia coli causing uncomplicated urinary tract infections: a European update for 2014 and comparison with 2000 and 2008. Infect Dis Ther. 2015;4(4):417-23.

24. Park SH, Byun JH, Choi SM, Lee DG, Kim SH, Kwon JC, et al. Molecular epidemiology of extended-spectrum $\beta$-lactamase-producing Escherichia coli in the community and hospital in Korea: emergence of ST131 producing CTX-M-15. BMC Infect Dis. 2012;12(1):1-11.

25. Xia S, Fan X, Huang Z, Xia L, Xiao M, Chen R, et al. Dominance of CTX-M-type extended-spectrum $\beta$ - lactamase (ESBL)-producing Escherichia coli isolated from patients with community-onset and hospital- onset infection in China. PLoS One. 2014;9(7):e100707.

26. Lakshminarayana SA, Chavan SKD, Prakash R, Sangeetha S. Bacterial pathogens in urinary tract infection and antibiotic susceptibility pattern from a Teaching Hospital, Bengaluru, India. Int J Curr Microbiol Appl Sci. 2015;4(11):731-6.

27. Mansouri S, Shareifi S. Antimicrobial resistance pattern of Escherichia coli causing urinary tract infections, and that of human fecal flora, in the Southeast of Iran. Microb Drug Resist. 2002;8(2):123-8.
28. Walker E, Lyman A, Gupta K, Mahoney MV, Snyder GM, Hirsch EB. Clinical management of an increasing threat: outpatient urinary tract infections due to multidrug-resistant uropathogens. Clin Infect Dis. 2016;63(7):960-5.

29. Melo DB, Menezes APO, Reis JN, Guimarães AG. Antimicrobial resistance and genetic diversity of Escherichia coli isolated from humans and foods. Braz J Microbiol. 2015;46(4):1165-70.

30. Leflon-Guibout V, Blanco J, Amaqdouf K, Mora A, Guize L, Nicolas-Chanoine MH. Absence of CTX-M enzymes but high prevalence of clones, including clone ST131, among fecal Escherichia coli isolates from healthy subjects living in the area of Paris, France. J Clin Microbiol. 2008;46(12):3900-5.

31. Marshall BM, Levy SB. Food animals and antimicrobials: impacts on human health. Clin Microbiol Rev. 2011;24(4):718-33.

32. Rodríguez-Baño J, Navarro MD, Romero L, Muniain MA, Perea EJ, Pérez-Cano R, et al. Clinical and molecular epidemiology of extended-spectrum $\beta$-lactamase-producing Escherichia coli as a cause of nosocomial infection or colonization: implications for control. Clin Infect Dis. 2006;42(1):37-45.

33. Briongos-Figuero LS, Gómez-Traveso $\mathrm{T}$, Bachiller-Luque $\mathrm{P}$, Domínguez-Gil González M, Gómez-Nieto A, Palacios-Martín T, et al. Epidemiology, risk factors and comorbidity for urinary tract infections caused by extended-spectrum beta-lactamase (ESBL)producing enterobacteria. Int J Clin Pract. 2012;66(9):891-6.

34. Woodford N, Ward ME, Kaufmann ME, Turton J, Fagan EJ, James D, et al. Community and hospital spread of Escherichia coli producing CTX-M extended-spectrum $\beta$-lactamases in the UK. J Antimicrob Chemother. 2004;54(4):735-43. 